\title{
Molecular Detection of Rifampicin and Isoniazid Resistance and Characterization of Mutations in Mycobacterium tuberculosis Complex using Line Probe Assay
}

\author{
Namratha W. Nandihal* and M.K. Anand \\ Department of Microbiology, Karnataka Institute of Medical Sciences, \\ Hubli, Karnataka, India \\ *Corresponding author
}

\begin{tabular}{|c|c|}
\hline & A B S T R A C T \\
\hline & \multirow{5}{*}{$\begin{array}{l}\text { India is high tuberculosis burdened country with increasing prevalence of multidrug } \\
\text { resistant tuberculosis. Rapid diagnosis and prompt treatment of infectious cases are the key } \\
\text { elements in reducing the spread of tuberculosis. In the present study we sought to ascertain } \\
\text { multidrug resistant tuberculosis among previously treated tuberculosis cases and its } \\
\text { resistance pattern to rifampicin and isoniazid genes. The samples from the patients of } \\
\text { previously treated tuberculosis cases were collected from eleven districts of North } \\
\text { Karnataka during July } 2013 \text { to December } 2013 \text { and transported to laboratory. The line } \\
\text { probe assay was carried out on } 265 \text { smear positive samples to detect common mutations in } \\
\text { the rpoB gene for rifampicin and katG and inhA genes for isoniazid, respectively. A total } \\
\text { of } 380 \text { sputum samples from MDR suspects were received of which, } 282 \text { ( } 74.2 \%) \text { isolates } \\
\text { were found to be AFB Smear positive. All smear positive sample processed showed } 102 \\
(36.2 \%) \text { resistant to rifampacin and } 107 \text { ( } 37.9 \%) \text { resistant to Isoniazid. Missing wild type } \\
8 \text { along with mutation in codon S531L was commonest pattern for rifampicin resistant } \\
\text { isolates and missing wild type along with mutations in codon S315T1 of kat } G \text { gene was } \\
\text { commonest pattern for isoniazid resistant isolates. The MDR-TB among previously treated } \\
\text { TB suspects tested in Northern Districts of Karnataka, India was found to be } 19.5 \% \text {. The } \\
\text { common mutations obtained for RIF and INH in the region was mostly similar to those } \\
\text { reported earlier in different parts of India. }\end{array}$} \\
\hline Keywords & \\
\hline Article Info & \\
\hline $\begin{array}{l}\text { Accepted: } \\
\text { 04 December } 2018 \\
\text { Available Online: } \\
\text { 10 January } 2019\end{array}$ & \\
\hline & \\
\hline
\end{tabular}

\section{Introduction}

Mycobacterium is a genus of Actinobacteria consists of the members of the Mycobacterium tuberculosis complex and more than 80 species of nontuberculosis mycobacteria, including pathogenic, opportunistic, and nonpathogenic species (Stauffer et al., 1995).
Tuberculosis (TB) caused by Mycobacterium tuberculosis is the second leading cause of death worldwide and remains a major global health problem. The global TB control is threatened by drug resistance with the emergence of multidrug resistant (MDR) and extensively drug resistant (XDR) TB (Udaykumar et al., 2014).

Conventional culture and drug susceptibility 
testing (DST) on solid media is a time consuming process and these systems have been supplemented with automated liquid culture systems in many diagnostic laboratories with decreased time to detection and greater sensitivity. However, the time for resistance testing is still about 14 to 21 days, beginning from the time that a positive culture is obtained (Piersimoni et al., 2006). The most rapid results could be achieved by molecular methods including commercial or in-house DNA hybridization or amplification methods which allow detection of Mycobacterium tuberculosis as well as drug resistance in clinical samples within five days (Hillemann et al., 2007).

The burden of MDR TB and XDR TB in India is not available as continuous surveillance for drug resistance is not carried out. This study was done to determine the drug resistance patterns to first line drugs among new and previously treated patients with TB.

\section{Materials and Methods}

All manipulations with potentially infectious clinical specimens were performed in a Class IIA Bio-safety cabinet in a BSL2 laboratory. Sputum specimens were decontaminated with $\mathrm{N}$-acetyl-L-cysteine-sodium hydroxide (Kent et al., 2007). After centrifugation, the pellet was suspended in $1.0 \mathrm{ml}$ of phosphate buffer ( $\mathrm{pH}$ 6.8). A concentrated smear was prepared and examined after AFB staining. Smear negative specimen was inoculated LJ Media. Specimens with a smear positive and culture positive recovered from smear negative sample inoculated were selected for MTBDRplus testing by Line Probe Assay.

GenoType MTBDRplus assay: The GenoType MTBDRplus line probe assay was carried out according to the manufacturer's specifications. The test is based on DNA strip technology and has three steps: DNA extraction, multiplex polymerase chain reaction (PCR) amplification, and reverse hybridization. A $500 \mathrm{ml}$ portion of the decontaminated sediment was used for DNA extraction, the process that included heating and centrifugation. The amplification procedure that consisted of preparation of the master mix and addition of extracted DNA. These steps were carried out in separate rooms with restricted access and unidirectional workflow. Hybridization was performed with the Twincubator (Hain Lifescience) semiautomated or GT Blot 48 (Hain Life science), which is automated hybridization machine (Hillemann et al., 2007). After hybridization and washing, strips were removed, allowed to air dry, and fixed on paper.

The MTBDRplus strips were interpreted according to manufacturer's guidelines. The strip contains 27 reaction zones (6 control probes and 21 probes for mutation). The control probes include a conjugate control (CC), amplification control (AC), $M$. tuberculosis complex control (TUB), rрoB amplification control, inhA amplification control and katG amplification control. For the detection of rifampicin resistance, the $r p o B$ gene (coding for the $\beta$-sub-unit of the RNA polymerase) and for high level INH resistance, the katG gene (coding for the catalase peroxidase) is examined and for detection of low level INH resistance, the promoter region of the inhA gene (coding for the NADH enoyl ACP reductase) is examined. For a valid result, all the six control bands should appear correctly. The absence of at least one of the wild-type bands or the presence of bands indicating a mutation implies that the sample tested is resistant to the particular antibiotic tested.

\section{Results and Discussion}

A total of 380 patients with 265 (69.7\%) male and $115(30.3 \%)$ female with a ratio 2.3:1, were enrolled and had specimens collected and sent to the testing laboratory. Although a 
well-administered DOTS strategy is the best method of preventing drug resistance and eventual treatment failure, it may not adequately treat resistant cases. There is an urgent need for timely identification of treatment failure on Category I regimen by early referral for culture and DST for prompt initiation of appropriate treatment to improve outcome as well as to sever the chain of primary transmission.

Among the 380 clinical samples included in this study, 265 showed AFB positive and 115 showed AFB negative. The microscopic results district wise are shown in Table 1. All Negative AFB specimens were inoculated on LJ Media, 17 (15\%) showed culture positive. All 265 smear positive samples and 17 cultures positive were positive for TUB band (M. tuberculosis complex control) in MTBDRplus assay. Out of 282 tested 147 (52\%) were susceptible to both INH and RIF, $74(26 \%)$ were MDR (resistant to INH and RIF), 33 (12\%) were resistant to INH and 28 (10\%) was only resistant to Rif. District wise breakdown of results are shown in Table 2 and age wise distribution of drug
Susceptibility result is shown in table 3 . In the present study, $19.5 \%$ of the isolates were MDR, which is lower than the $33.3 \%$ reported in a previous study in 1990-1991 (Jain et al., 1992) and much lower than $47.1 \%$ reported in a study in delhi-2009 (Hanif et al., 2014). The major limitation of the present study is the small sample size and therefore, it is not representative of the population at large. In fact, this limitation was observed in most previous studies on MDR-TB.

Pattern of gene mutations detected by GenoType MTBDRplus assay for RIF region and INH region are given in Table 4 and 5 respectively. Many recent studies have already demonstrated the feasibility of MTBDRplus assay as an effective tool in early detection of MDR TB and have good concordance with phenotypic drug susceptibility results (Burnard et al., 2008; Lacoma et al., 2008; Miotto et al., 2006). The present study has evaluated the assay in a geographic region, which is endemic for $M$. tuberculosis and studied the frequent mutations leading to drug resistance (Fig. 1).

Table.1 District-wise distribution of AFB smear positive and negative samples with culture positive; AFB and culture reporting as per RNTCP guidelines

\begin{tabular}{|c|c|c|c|c|c|c|c|}
\hline \multirow[t]{2}{*}{ District } & \multirow{2}{*}{$\begin{array}{c}\text { Total } \\
\text { sample }\end{array}$} & \multicolumn{4}{|c|}{ Smear Positive } & \multirow{2}{*}{$\begin{array}{c}\text { Smear } \\
\text { Negative }\end{array}$} & \multirow{2}{*}{$\begin{array}{l}\text { Culture } \\
\text { positive }\end{array}$} \\
\hline & & $3+$ & $2+$ & $1+$ & Scanty & & \\
\hline Bagalkot & 18 & 10 & 4 & 2 & 1 & 1 & 0 \\
\hline Belgaum & 32 & 11 & 2 & 4 & 1 & 14 & 1 \\
\hline Bidar & 22 & 13 & 5 & 1 & 0 & 3 & 0 \\
\hline Bijapur & 24 & 13 & 5 & 2 & 1 & 3 & 1 \\
\hline Davangere & 27 & 9 & 7 & 1 & 1 & 9 & 1 \\
\hline Dharwad & 66 & 21 & 10 & 11 & 1 & 23 & 6 \\
\hline Gadag & 32 & 13 & 4 & 9 & 0 & 6 & 1 \\
\hline Gulbarga & 27 & 12 & 4 & 6 & 1 & 4 & 1 \\
\hline Haveri & 18 & 11 & 1 & 2 & 2 & 2 & 0 \\
\hline Karwar & 83 & 12 & 11 & 15 & 4 & 41 & 5 \\
\hline Yadgiri & 31 & 13 & 3 & 5 & 1 & 9 & 1 \\
\hline Total & 380 & 138 & 56 & 58 & 13 & 115 & 17 \\
\hline
\end{tabular}


Table.2 District wise distribution of Rifampicin and isoniazid susceptibility result using GenoType MTBDRplusHain Life (Sciences, Nehran, Germany) Version 2.0

\begin{tabular}{|c|c|c|c|c|c|}
\hline \multirow[t]{2}{*}{ District } & \multirow{2}{*}{$\begin{array}{c}\text { Total } \\
\text { LPA } \\
\text { Processed }\end{array}$} & \multicolumn{4}{|c|}{ Drug Susceptibility result } \\
\hline & & MDR & $\begin{array}{c}\text { Mono- RIF } \\
\text { resistance }\end{array}$ & $\begin{array}{c}\text { Mono-INH } \\
\text { resistance }\end{array}$ & $\begin{array}{c}\text { RIF \& INH } \\
\text { sensitive }\end{array}$ \\
\hline Bagalkot & 17 & $7(41.2 \%)$ & $2(11.7 \%)$ & 0 & $8(47.1 \%)$ \\
\hline Belgaum & 19 & $4(21.1 \%)$ & $3(15.8 \%)$ & 0 & $12(63.1 \%)$ \\
\hline Bidar & 19 & $3(15.8 \%)$ & $4(21.1 \%)$ & $5(26.3 \%)$ & $7(36.8 \%)$ \\
\hline Bijapur & 22 & $5(22.8 \%)$ & $3(13.6 \%)$ & $3(13.6 \%)$ & $11(50 \%)$ \\
\hline $\begin{array}{c}\text { Davanger } \\
\text { e }\end{array}$ & 19 & $5(26.3 \%)$ & $3(15.8 \%)$ & $1(5.3 \%)$ & $10(52.6 \%)$ \\
\hline Dharwad & 49 & $9(18.3 \%)$ & $4(8.2 \%)$ & $4(8.2 \%)$ & $32(65.3 \%)$ \\
\hline Gadag & 27 & $6(21.4 \%)$ & $1(3.6 \%)$ & $8(28.6 \%)$ & $12(42.8 \%)$ \\
\hline Gulbarga & 24 & $8(33.4 \%)$ & $2(8.3 \%)$ & $5(20.8 \%)$ & $9(37.5 \%)$ \\
\hline Haveri & 16 & $5(31.3 \%)$ & $2(12.5 \%)$ & $1(6.2 \%)$ & $8(50 \%)$ \\
\hline Karwar & 47 & $11(22 \%)$ & $2(4 \%)$ & $2(4 \%)$ & $32(64 \%)$ \\
\hline Yadgiri & 23 & $11(47.8 \%)$ & $2(8.7 \%)$ & $4(17.4 \%)$ & $6(26.1 \%)$ \\
\hline Total & 282 & $74(25.9 \%)$ & $28(9.8 \%)$ & $33(11.5 \%)$ & $147(51.4 \%)$ \\
\hline
\end{tabular}

Table.3 Age wise distribution of Rifampicin and isoniazid susceptibility result using GenoType MTBDRplusHain Life (Sciences, Nehran, Germany) Version 2.0

\begin{tabular}{|c|c|c|c|c|c|c|}
\hline \multirow{2}{*}{ Age } & \multicolumn{5}{|c|}{ Drug Susceptibility result } & \multirow{2}{*}{ Total } \\
\cline { 2 - 7 } & MDR-TB & $\begin{array}{c}\text { RIF } \\
\text { Resistance }\end{array}$ & $\begin{array}{c}\text { INH } \\
\text { Resistance }\end{array}$ & $\begin{array}{c}\text { Sensitive for } \\
\text { Rif \& INH }\end{array}$ & $\begin{array}{c}\text { Negative } \\
\text { for TB }\end{array}$ & \\
\hline Pediatrics & $5(1.3 \%)$ & $1(0.2 \%)$ & 0 & $9(2.4 \%)$ & $11(2.9 \%)$ & $\mathbf{2 6}(\mathbf{7} \%)$ \\
\hline Age 19-30 & $38(10 \%)$ & $9(2.4 \%)$ & $10(2.6 \%)$ & $42(11.1 \%)$ & $24(6.3 \%)$ & $\mathbf{1 2 3}(\mathbf{3 2} \%)$ \\
\hline Age 31-40 & $13(3.4 \%)$ & $9(2.4 \%)$ & $7(1.9 \%)$ & $46(12.2 \%)$ & $21(5.5 \%)$ & $\mathbf{9 6}(\mathbf{2 5} \%)$ \\
\hline Age 41-50 & $5(1.3 \%)$ & $7(1.9 \%)$ & $7(1.9 \%)$ & $26(6.8 \%)$ & $29(7.6 \%)$ & $\mathbf{7 4}(\mathbf{2 0} \%)$ \\
\hline Age 51-60 & $9(2.4 \%)$ & 0 & $8(2.1 \%)$ & $17(4.3 \%)$ & $7(1.9 \%)$ & $\mathbf{4 1}(\mathbf{1 1} \%)$ \\
\hline $\begin{array}{c}\text { 61 and } \\
\text { above }\end{array}$ & $4(1.1 \%)$ & $2(0.5 \%)$ & $1(0.2 \%)$ & $7(1.9 \%)$ & $6(1.5 \%)$ & $\mathbf{2 0}(\mathbf{5} \%)$ \\
\hline Total & $\mathbf{7 4}(\mathbf{1 9 . 5} \%)$ & $\mathbf{2 8}(\mathbf{7} \%)$ & $\mathbf{3 3}(\mathbf{8 . 5} \%)$ & $\mathbf{1 4 7}(\mathbf{3 9} \%)$ & $\mathbf{9 8}(\mathbf{2 6} \%)$ & $\mathbf{3 8 0}$ \\
\hline
\end{tabular}


Table.4 Pattern of gene mutations detected by GenoType MTBDRplus assay (Hain Life Sciences, Nehran, Germany) Version 2.0 in drug resistant M. tuberculosis. Mutations in the rpoB gene and the corresponding wild type and mutation bands

\begin{tabular}{|c|c|c|c|c|c|c|}
\hline Gene & \multicolumn{6}{|c|}{ ropB } \\
\hline $\begin{array}{c}\text { Failing Wild } \\
\text { type band(s) }\end{array}$ & WT 8 & \multicolumn{2}{|c|}{ WT 7 } & WT 3 \& 4 & WT 2 & + \\
\hline $\begin{array}{c}\text { Codon } \\
\text { analysed }\end{array}$ & $530-533$ & \multicolumn{2}{|c|}{$526-529$} & $\begin{array}{c}513-517, \\
516-519\end{array}$ & $510-513$ & NA \\
\hline $\begin{array}{c}\text { Developing } \\
\text { Mutation } \\
\text { Band }\end{array}$ & Mut 3 & Mut 2A & Mut 2B & Mut 1 & UK* & Mut 2A \\
\hline $\begin{array}{c}\text { Mutation } \\
\text { MDR-TB }\end{array}$ & S531L & H526Y & H526D & D516V & UK* & H526Y \\
\hline $\begin{array}{c}\text { Mono RIF } \\
\text { Resistance }\end{array}$ & 15 & 0 & 10 & 12 & 4 & 0 \\
\hline Total & 60 & 3 & 12 & 18 & 6 & 3 \\
\hline
\end{tabular}

*UK: No known mutations as defined by the kit

Table.5 Pattern of gene mutations detected by GenoType MTBDRplus assay (Hain Life Sciences, Nehran, Germany) Version 2.0 in drug resistant M. tuberculosis. Mutations in the katG gene and inhA promoter region with the corresponding wild type and mutation bands

\begin{tabular}{|c|c|c|c|c|c|c|c|}
\hline Gene & \multicolumn{3}{|c|}{ katG } & \multicolumn{4}{c|}{ inhA } \\
\hline $\begin{array}{c}\text { Failing Wild } \\
\text { type band(s) }\end{array}$ & \multicolumn{2}{|c|}{ WT 1 } & + & WT 1 & WT 2 & \multicolumn{2}{|c|}{} \\
\hline $\begin{array}{c}\text { Codon } \\
\text { analysed }\end{array}$ & \multicolumn{2}{|c|}{315} & NA & -15 & -8 & NA & NA \\
\hline $\begin{array}{c}\text { Developing } \\
\text { Mutation } \\
\text { Band }\end{array}$ & Mut 1 & UK $^{*}$ & Mut 1 & Mut 1 & Mut 3B & Mut 1 & Mut 3A \\
\hline $\begin{array}{c}\text { Mutation } \\
\text { MDR-TB }\end{array}$ & S315T1 & UK $^{*}$ & S315T1 & C15T & T8A & C15T & T8C \\
\hline $\begin{array}{c}\text { Mono RIF } \\
\text { Resistance }\end{array}$ & 24 & 2 & 2 & 2 & 6 & 0 & 0 \\
\hline Total & 88 & 3 & 4 & 4 & 9 & 2 & 1 \\
\hline
\end{tabular}

*UK: No known mutations as defined by the kit 
Figure.1 Representative patterns of line probe assay (GenoType MTBDR-plus) strip. Lane 1, MDR- TB (rpoB S531L mutation and inhA C15T mutation); Lane 2, rifampicin monoresistant (rpoB S531L mutation); Lane 3, MDR- TB (rpoB S531L mutation and KatG S315T1 mutation);

Lane 4, MDR- TB (rpoB H526D mutation and katG S315T1 mutation); Lan 5, isoniazid monoresistant (katG S315T1 mutation); Lane 6, MDR- TB (rpoB S531L mutation and inhA C15T mutation); Lane 7, susceptible to rifampicin (RIF) and isoniazid (INH); Lane 8, MDR- TB (rpoB S531L mutation and $\mathrm{KatG}$ S315T1 mutation)

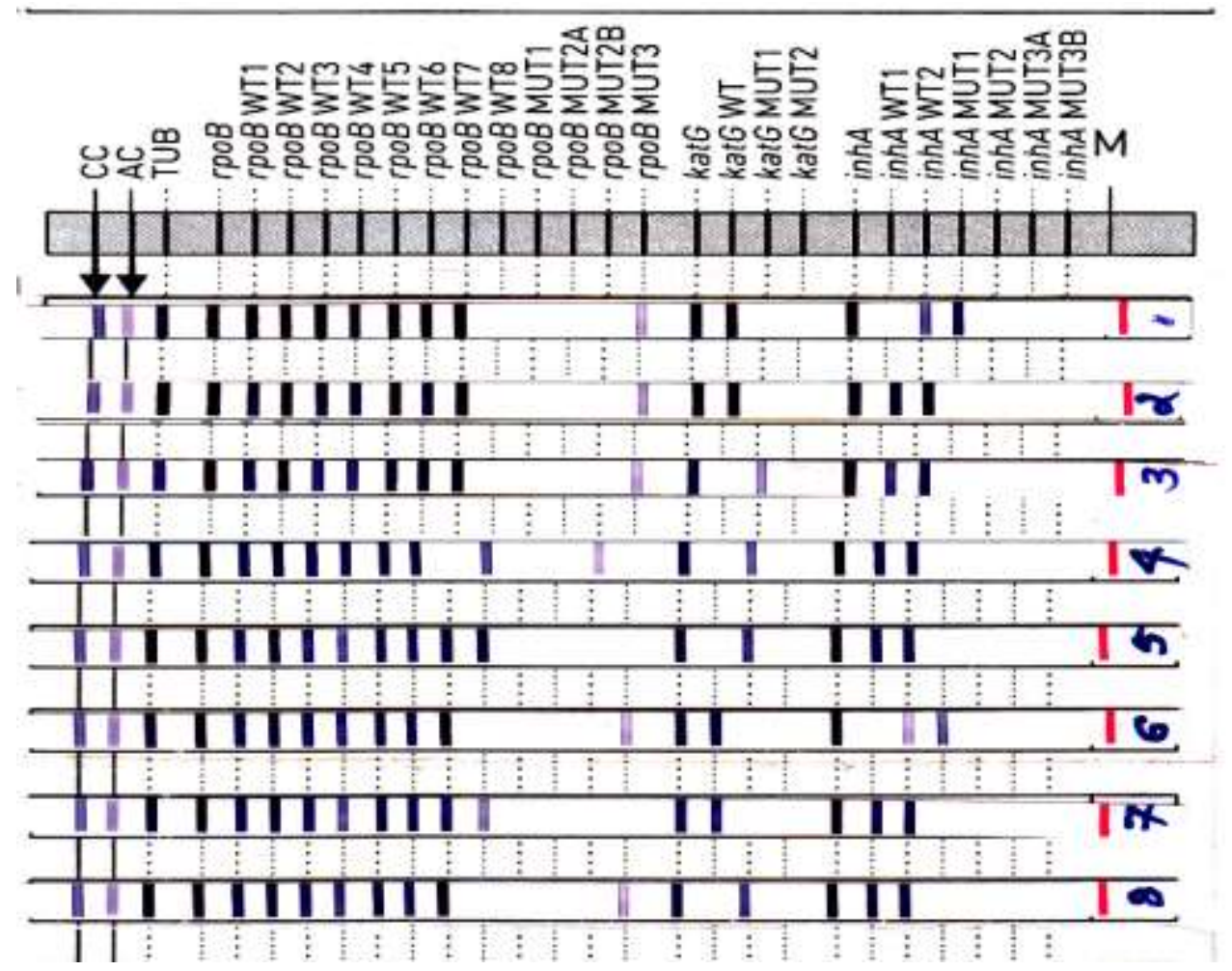

In conclusion, the study, the first of its kind from North Karnataka, a geographic region with high prevalence of tuberculosis, has shown MTBDRplus assay has good sensitivity and specificity in detecting MDR TB cases in our settings.

This study underscores the need for DST in all TB patients particularly in the previously treated patients. New drugs, novel treatment strategies and adherence to treatment are needed to effectively treat and control drug resistant TB. Molecular methods which allow rapid detection of tuberculosis as well as drug resistance directly from clinical samples have become the most popular diagnostic methodology with the emergence of multidrug resistant tuberculosis. MTBDRplus assay had good sensitivity and specificity with turnaround time of less than a week. It may be a useful tool for rapid detection of multidrug resistant tuberculosis.

\section{Acknowledgment}

Authors acknowledge the technical support and financial support of Foundation of Innovative Diagnostics (FIND), India in the study.

\section{References}

Burnard, M., Albert, H., Coetzee, G., O’Brien, R., Bosman, M.E. 2008. 
Rapid molecular screening for multidrug-resistant tuberculosis in a high-volume public health laboratory in South Africa. Am J Respir Crit Care Med. 177: 787-792.

Hanif, M., Malik, S., Dhingra, V.K. 2009. Acquired drug resistance pattern in tuberculosis cases at the State Tuberculosis Centre, Delhi, India. INT J Tuberc Lung Dis. 13(1): 74-78

Hillemann, D., Rusch-Gerdes, S., Richter, E. 2007. Evaluation of the GenoType MTBDRplus assay for rifampin and isoniazid susceptibility testing of Mycobacterium tuberculosis strains and clinical specimens. J Clin Microbiol. 45: 2635-2640.

Jain, N.K., Chopra, K.K., Prasad G. 1992. Initial and acquired isoniazid and rifampicin resistance to $M$. tuberculosis and its implications for treatment. Indian J Tuberc. 39: 121124.

Kent, P.T., Kubica, G.P. 1985. Public health mycobacteriology: a guide for the level III laboratory. Atlanta, GA: Centers for Disease Control.

Lacoma, A., Garcia-Sierra, N., Prat, C., RuizMunzano, J., Haba, L., Roses, S., et al., 2008. Genotype MTBDRplus assay for molecular detection of rifampin and isoniazid resistance in Mycobacterium tuberculosis strains and clinical samples. J Clin Microbiol. 46: 3660-3667.

Miotto, P., Piana, F., Penati, V., Canducci, F.,
Migliori, G.B., Cirillo, D.M. 2006. Use of GenoType MTBDR assay for molecular detection of rifampicin and isoniazid resistance in Mycobacterium tuberculosis clinical strains isolated in Italy. J Clin Microbiol. 44: 2485-2491.

Piersimoni, C., Olivieri, A., Benacchio, L., Scarparo, C. 2006. Current perspectives on drug susceptibility testing of Mycobacterium tuberculosis complex: The automated nonradiometric systems. J Clin Microbiol. 44: 20-28.

Stauffer, F., Mutschlechner, R., Hasenberger, P., Stadlbauer, S., Schinko, H. 1995. Detection of Mycobacterium tuberculosis complex in clinical specimens by a commercial polymerase chain reaction kit. Eur $\mathrm{J}$ Clin Microbiol Infect Dis. 14: 10461051.

Udaykumar, A. J., Jayashree, R., Baijayanti, M., Rosario, V., John, K. 2014. Drug resistance patterns in new and previously treated patients with tuberculosis presenting to a tertiary care center in southern India. BMC Infectious Diseases. 14 (Suppl 3):O3.

Watterson, S.A., Wilson, S.M., Yates, M.D., Drobniewski, F.A. 1998. Comparison of three molecular assays for rapid detection of rifampicin resistance in Mycobacterium tuberculosis. J Clin Microbiol. 36: 1969-1973.

\section{How to cite this article:}

Namratha W. Nandihal and Anand, M.K. 2019. Molecular Detection of Rifampicin and Isoniazid Resistance and Characterization of Mutations in Mycobacterium tuberculosis complex using Line Probe Assay. Int.J.Curr.Microbiol.App.Sci. 8(01): 465-471.

doi: https://doi.org/10.20546/ijcmas.2019.801.049 